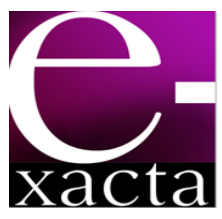

ISSN: 1984-3151

\title{
Análise da Centralidade da Ceasa Minas em RELAÇÃo AOS FLUXOS HORTIGRANJEIROS EM MINAS GERAIS
}

\author{
Analysis of Centrality of Ceasa Minas Relativep to flows \\ HORTICULTURE IN MinAS GERAIS
}

\author{
Sérgio Gontijo Faria'; Antônio Carlos da Silva Souza ${ }^{2}$ \\ 1 Graduado em Geografia. UniBH, 2013. Belo Horizonte, MG. \\ sergiogfaria@yahoo.com.br. \\ 2 Mestre em Geografia - Tratamento da Informação Espacial. \\ PUC Minas, 2008. Professor Assistente do Centro \\ Universitário de Belo Horizonte - UniBH. Belo Horizonte, \\ MG. antonio.c.souza@prof.unibh.br.
}

Recebido em: 12/09/2014 - Aprovado em: 20/11/2014 - Disponibilizado em: 30/11/2014

RESUMO: Este trabalho pretende estudar a centralidade da Ceasa Minas em relação aos fluxos de hortigranjeiros no Estado de Minas Gerais, considerando o aumento da produção e o distanciamento das zonas produtoras.

PalAVRAS-CHAVE: Fluxos de hortigranjeiros. Centralidade. CeasaMinas.

ABSTRACT: This study aims to confirm or reject the centrality of Ceasa Minas in relation to flows of horticulture in the state of Minas Gerais, considering the increased production and detachment from producing areas.

KEYWORDS: Flow horticulture. Centralization. CeasaMinas.

\section{INTRODUÇÃO}

A análise que se pretende fazer neste trabalho parte do pressuposto de que uma Central de Distribuição de Alimentos deveria ocupar uma posição de centralidade em relação aos fluxos de entrada e saída de produtos, de forma efetiva no atendimento às necessidades e demandas do mercado. Desta forma, este trabalho pretende fazer uma análise atualizada das condições pertinentes aos sistemas de produção e comercialização relacionados à localização dos entrepostos da Central de Distribuição de Alimentos de Minas Gerais - CEASA Minas.

Para tal, pretende-se identificar a posição da Central de Abastecimento de Minas Gerais em relação aos fluxos de distribuição de hortigranjeiros, ou seja, os principais pontos de produção hortícola do Estado de
Minas Gerais. Entre os objetivos específicos, pode-se citar a análise da localização das zonas de produção, das vias de acesso da localização dos principais centros consumidores e o papel das filiais do CEASA no interior de Minas Gerais neste processo.

Em Minas Gerais, a Central de Distribuição de Alimentos está localizada na região metropolitana da capital, geograficamente situada na região central do Estado, o que favorece a atividade proposta.

Ressalta-se que na época e na condição de sua criação não se consideravam as questões de logística e da centralidade para um centro de distribuição, apenas o fato de se localizar na capital do Estado.

O problema central deste trabalho é confirmar se a Ceasa Minas ainda mantém a centralidade dos fluxos de hortigranjeiros no Estado de Minas Gerais, mesmo 
ocorrendo alterações na localização das zonas produtoras, que muitas vezes se distanciam da região metropolitana de Belo Horizonte.

A discussão parte do pressuposto de que um ponto de distribuição deve ser bem localizado em função tanto dos aspectos de fornecedores quanto de consumidores, principalmente no que se refere a alimentos perecíveis "hortigranjeiros". Quando se trata de vegetais, cada quilômetro de deslocamento refletese diretamente na qualidade dos alimentos. Desta forma, conhecer o nível de centralidade da Ceasa Minas em relação aos fluxos dos hortigranjeiros pode influenciar na gestão estratégica de abastecimento.

\section{História da CEASA no Brasil}

Até a década de 1960, a comercialização de produtos hortigranjeiros nos grandes centros era uma atividade informal. Produtores locais traziam suas colheitas esporádicas e ofereciam seus produtos em pontos estratégicos em relação ao fluxo de pessoas ou através de entregas em domicílios.

Com o crescimento da população urbana, em função dos processos de migração interna do Brasil, ocorreram transformações significativas nas atividades ligadas à comercialização de produtos alimentícios (ABRACEN, 2011).

Os novos habitantes das grandes cidades vinham de localidades rurais diversas com costumes alimentares também diferentes, o que transformou radicalmente a oferta de produtos hortigranjeiros nos grandes centros. Nesta ocasião, nas grandes cidades e capitais, o espaço reservado a este tipo de comércio geralmente eram as praças próximas às estações ferroviárias ou rodoviárias, onde se instalavam feiras bastante movimentadas (SÃO PAULO MINHA CIDADE, 2012).

Não demorou muito para que as feiras passassem a sofrer transformações ligadas ao crescimento da demanda e da oferta de gêneros alimentícios, principalmente dos hortigranjeiros; estes eram produtos de baixo valor e de grande procura pelas classes operárias da época, o que causava grande movimentação de pessoas nestes locais, tumultuando as praças e interferindo na paisagem das cidades.

A criação dos mercados municipais passou a ser vista como uma solução urbanística para os problemas das capitais naquela época. Com o objetivo de reunir em um local fisicamente delimitado todas as atividades comerciais que envolviam produtos hortigranjeiros, esperava-se resolver todos os problemas deste setor.

Nesta época, a população urbana continuava a crescer, fruto da melhoria das condições de vida nas cidades e do êxodo rural. Este crescimento se refletia na expansão dos limites urbanos com a ocupação das áreas das periferias, mudando as estruturas tradicionais e surgindo novas atividades econômicas. $O$ aumento da procura de gêneros alimentícios fez crescer também a oferta das mercadorias, que eram direcionadas aos mercados municipais, que nesta ocasião começavam a funcionar como uma espécie de centro de distribuição para os diversos mercados, feiras e armazéns que se instalavam nos bairros mais distante do centro (SÃO PAULO MINHA CIDADE, 2012).

Estas atividades passaram a ter grandes proporções, causando, assim, significativas transformações no ambiente, gerando diversos problemas como sobrecarga do trânsito, lixo em grande escala, especulação comercial, falta de qualidade nos produtos, entre outros, o que resultou em uma desordem generalizada, tanto do setor de fornecimento de gêneros alimentícios quanto do ambiente urbano ocupado pelos mercados (ABRACEN, 2011).

Sendo assim, no final da década de 1960, a comercialização de produtos hortigranjeiros estava totalmente desorganizada, chegando a ser 
marginalizada. "Tão marginal que a comercialização se dava na rua, literalmente" (ABRACEN, 2011).

Esta situação era comum em todos os grandes centros, em alguns mais que outros, mas não deixava de ser um problema. A situação se tornava crítica principalmente nas capitais dos Estados, chamando a atenção do Governo Federal, que identificou esta situação como um grande estrangulamento do sistema de comercialização de hortigranjeiros.

A partir daí a questão da comercialização de hortigranjeiros passa a ser tratada de forma diferente. O próprio Governo Federal participa efetivamente da busca de soluções: "O Ministério do Planejamento criou, através do decreto 61.391 de 20/9/67, um Grupo de Estudo que propôs um Plano Decenal de Desenvolvimento Econômico, cujo estudo apresenta uma definição clara de CEASA: Ponto de reunião de agentes de comercialização" (ABRACEN, 2011).

Na década de 1970, foi criado pelo decreto 70.502 de 11/05/1972 o Sistema Nacional de Centrais de Abastecimento - SINAC. Seus objetivos eram no sentido de organizar a distribuição e comercialização de produtos agrícolas, desenvolver condições operacionais para coleta, análise e divulgação de informações do mercado agrícola. Tinha também como objetivo reduzir o custo para o varejo e interferir na flutuação da oferta de produtos, o que se refletiria na resolução dos problemas urbanísticos causadas pela comercialização atacadista nas regiões centrais das grandes cidades (ABRACEN, 2011).

O Governo Federal delegou à Companhia Brasileira de Alimentos (COBAL) a gestão do SINAC, que implanta o Plano Nacional de Desenvolvimento - PND -, no qual estaria prevista a construção de 21 CEASAS (Centrais de Abastecimento S/A) a serem implantadas nas principais cidades brasileiras. As empresas eram de economia mista, sendo os acionistas a União, os estados e os municípios onde se localizavam as sedes (ABRACEN 2011).
A elaboração dos projetos iniciais teve a assessoria da FAO (Organização das Nações Unidas para Alimentação e Agricultura), entre outros organismos internacionais que facilitaram o treinamento de técnicos da Cobal e dos governos estaduais nos Estados Unidos e na Europa (ABRACEN, 2011).

\subsection{História da CEASA Minas}

A criação da Ceasa teve seu processo iniciado em 1970, por meio da Lei estadual № 5.577 , a Centrais de Abastecimento de Minas Gerais - CEAM. Uma área de aproximadamente 229 ha foi expropriada em Contagem, através do decreto estadual expropriatório № 12.461, para implantação da Ceasa. No início do ano de 1971, foi constituída a Ceasa/MG, que passa a funcionar na Av. João Pinheiro, 39, em Belo Horizonte (CEASAMINAS, 2012).

O funcionamento da unidade da Ceasa Minas na Grande BH, no município de Contagem, teve início em 1974, sendo inaugurada em dezembro daquele ano. Sua estrutura era de porte extraordinário, com 16 pavilhões destinados aos atacadistas e distribuidores de frutas e legumes, e ainda contava com um galpão de $2.800 \mathrm{~m}^{2}$, onde funcionaria o Mercado Livre do Produtor (MLP), área exclusiva para os produtores comercializarem seus produtos diretamente com o distribuidor ou consumidor (CEASAMINAS, 2012).

Em 1975, uma segunda fase do Plano Nacional de Desenvolvimento passa a ser implantada, voltada para o aperfeiçoamento operacional do sistema. Nesta ocasião a Ceasa Minas expandia-se, e em 1978 são inauguradas as unidades de Uberlândia, no Triângulo Mineiro, e Caratinga, na Região do Vale do Rio Doce; em 1979 é inaugurada a unidade de Juiz de Fora, no Alto do Rio Doce, buscando assim maior integração com as zonas produtoras e o sistema de distribuição de hortigranjeiros (ABRACEN, 2011). 
$\mathrm{Na}$ década de 1980, a Ceasa expandiu suas atividades, quando passou a contar com 37 pavilhões, mais o pavilhão Shopping, o edifício Minas Bolsa e fez a primeira expansão do MLP, fato repetido por duas vezes na década de 1990.

Em 2004 a Ceasa Minas assume a gerência da Ceasa de Barbacena, que era dirigida por uma associação de produtores de Barbacena, completando assim 5 unidades no interior do Estado. Nesta ocasião a Ceasa Minas atingia 1.500.000 toneladas de produtos hortigranjeiros ofertados em todas as unidades (CEASAMINAS, 2012).

Quatro décadas passaram-se, a Ceasa Minas se afirmou como a terceira maior central de distribuição de hortigranjeiros e como a mais diversificada do país (PROHORT, 2011). Da mesma forma evoluíram e diversificaram as áreas de produção de hortigranjeiros no Estado, afastando-se dos limites da metrópole e adaptando-se a locais com aptidões específicas por diversas regiões de Minas Gerais. As vias de acessos, as formas de transporte também se alteraram durante este tempo.

\section{A dinÂmica de uma Central de DistribuiçÃo de Alımentos}

Os entrepostos atacadistas de hortigranjeiros, neste caso as CEASA's, podem ser definidos como um espaço onde se reúnem compradores, vendedores, produtores, comerciantes, consumidores, prestadores de serviços e agentes públicos em uma intensa relação comercial e social que é realizada em um curto espaço de tempo (PROHORT, 2011).

Para que haja esta relação, é necessário um lugar acessível a este público diversificado e que acolha a movimentação dos produtos envolvidos nas suas relações. A Ceasa Minas, unidade de Contagem, recebe cerca de 130 produtos hortigranjeiros vindos de 400 municípios de Minas Gerais, que são distribuídos para municípios do Espírito Santo, Rio de Janeiro, Bahia e para quase todos os municípios de Minas Gerais (CUNHA; CAMPOS, 2009).

\subsection{Centralidade}

A centralidade é uma prática social, que tem seus primeiros indícios nas ações de recolhimento e coleção de objetos e alimentos da natureza. Pode-se entender a centralidade como um fenômeno urbano, pois a cidade centraliza tudo que nasce da natureza e do trabalho noutros lugares. A centralidade é muito mais que um conceito, "é um aspecto racional da produção que não coincide com a atividade produtiva, mas dela não se dissocia”. (LEFEBVRE, 2008).

A centralidade referida neste trabalho está ligada à produção agrícola. Os itens são produzidos na zona rural do Estado e transportados até um centro urbano. Este deve ter um porte relativamente maior e uma boa relação de intercâmbio com outras localidades; isso determina a este centro urbano a condição de lugar central na região abrangida por esta relação. Beaujeu-Garnier (1997) cita a Teoria de "Lugar Central" de Christaller, segundo a qual a repartição das cidades e sua dimensão são condicionadas pela necessidade de servir o conjunto de uma população, isto é, pelo seu papel de Lugar Central.

O conceito vai se encorpando ao ser analisado dentro de suas relações espaciais. Segundo Duarte (2003), a centralidade é um fenômeno que abrange várias dimensões, que enriquecem o conceito de lugar geográfico. O caráter central de um espaço está associado à sua acessibilidade, enquanto o fator primordial para sua qualificação é sua localização.

A Ceasa Minas é um ponto de recebimento de mercadorias de diversos fornecedores, de múltiplas localidades de Minas Gerais e outros Estados, para serem comercializados num único local. Sua abrangência de relacionamento é expressiva, pois se 
localiza no 4ํㅡㄹ maior Estado em extensão do país, com mais de $580.000 \mathrm{~km}^{2}$, com 853 municípios (IBGE, 2010), onde as distâncias passam a ser superadas em benefício dos interesses econômicos.

\subsection{FLuXos}

A definição de fluxos é vista por diversos autores como movimento, mas um movimento mais complexo e intrincado, um sistema que transfere bens, serviços, informações, pessoas, valores, produtos, entre outros. Os fluxos de hortigranjeiros são bastante específicos, pela destinação e procedência dos produtos, isto é, são importantes para a alimentação de populações, mas também se configuram numa importante fonte de renda para as localidades onde são produzidos.

A relação é bem definida por Santos (1997) quando esse indica que os fluxos são o movimento e a circulação, que explicam também os fenômenos da distribuição e do consumo. Essa definição descreve em parte o tipo de fluxo que se pretende analisar, pois a movimentação de gêneros alimentícios, em especial os hortigranjeiros, estabelece uma conexão econômica entre o rural e o urbano.

Esta interação espacial rompe com limites espaciais de análise e, conforme Cocco (2009), está diretamente relacionada aos fluxos que não seguem uma determinada escala, tornando mais complexo este movimento, principalmente quando ocorrem alterações das zonas produtoras por algum motivo.

Já Martins (2006) afirma que é por meio dos fluxos que as atividades comerciais estabelecem o seu território. Este se configura por meio dos mercados atingidos nas compras, vendas e trocas de capitais e informações, mostrando que a formação de territórios pelos fluxos constitui uma escala da Geografia.

Em uma análise de Santos (1997), os elementos do espaço (indústrias, casas, comércios, empresas, propriedades rurais) aparecem como forma de materialização do capital, são fixos e fluxos que compõem e dão movimento ao espaço. O fluxo, portanto, indica mais que o simples movimento, indica as articulações do mercado que determinam níveis de oferta e procura, estando ligado ao transporte e suas implicações logísticas.

\section{Metodologia}

A questão da centralidade em relação aos fluxos de hortigranjeiros é um assunto pouco estudado no campo acadêmico, portanto este trabalho foi desenvolvido com bases nos dados coletados na própria Ceasa Minas, o que confere um caráter exploratório à pesquisa.

O processo de controle de entrada de produtos hortigranjeiros nos entrepostos da Ceasa Minas é feito por documentos específicos (Notas Fiscais e/ou Romaneios), os quais trazem informações básicas, como: dados cadastrais do produtor, identificação e quantidade do produto e procedência e destinação da mercadoria. Mediante estes dados, o Departamento Técnico - DETEC -, através da Seção de Informações de Mercado - SECIM-, contabiliza diariamente as quantidades e a procedência de todos os hortigranjeiros, compostos atualmente por 174 produtos diferentes.

Os dados disponíveis, a partir de 1981, são utilizados pela Ceasa Minas como subsídio para gerar informações e dados estatísticos referentes ao mercado de hortigranjeiros, fornecendo parâmetros de oferta e procura destes produtos nos níveis local, regional e nacional. Para efeitos práticos, o SECIM considera os hortigranjeiros divididos em três grandes grupos, conforme a Tabela 1. Procurou-se seguir o mesmo procedimento no levantamento dos dados, usando as mesmas categorias de produtos. 
Tabela 1

Grupos de Hortigranjeiros

\begin{tabular}{c|l}
\hline Grupo & \multicolumn{1}{|c}{ Característica } \\
\hline \multirow{2}{*}{ Hortaliças } & Folhas, flores e hastes \\
\cline { 2 - 2 } & Frutos \\
\cline { 2 - 2 } & Raiz, bulbos, tubérculos, rizomas \\
\hline \multirow{2}{*}{ Frutas } & Brasileira \\
\cline { 2 - 2 } & Importada \\
\hline Aves e Ovos & Ovos \\
\hline \multicolumn{2}{|c}{ Fonte: DETEC/SECIM/Ceasa Minas -2012 }
\end{tabular}

A diversidade dos hortigranjeiros e a grande quantidade de municípios fornecedores durante um período relativamente longo resultaram em um grande volume de informações. Desta forma foi necessário adotar um sistema de amostragem que conseguisse representar os fluxos de produtos da forma mais fidedigna. Optou-se pela escolha dos hortigranjeiros que se enquadrassem em duas importantes categorias e que atendessem a critérios qualitativos e quantitativos, conforme a Tabela 2.

Tabela 2

Categorias e critérios de escolha

\begin{tabular}{c|l}
\hline Categorias & \multicolumn{1}{|c}{ Critérios } \\
\hline \multirow{2}{*}{ Produto } & $\begin{array}{l}\text { Maior volume anual; representação de } \\
\text { cada tipo específico de hortigranjeiros }\end{array}$ \\
\hline \multirow{3}{*}{ Município } & $\begin{array}{l}\text { Fornecimento anual mínimo de } 7 \\
\text { meses; produção igual ou superior a } \\
\text { 3.000 t/ano }\end{array}$ \\
\hline \multicolumn{2}{c}{ Fonte: CEASA MINAS, 2012. } \\
Adaptado por: Sérgio Gontijo Faria
\end{tabular}

Nesta classificação procurou-se identificar eventuais alterações das zonas produtoras e as variações da produção dos principais produtos comercializados. Neste sentido, verificou-se a necessidade de adequação dos dados relativos às variedades de dois produtos: banana prata e tomate longa vida. Estes são variedades mais recentes e não constam nas duas primeiras décadas, quando figuravam como "banana nanica" e "tomate santa cruz"; desta forma, as duas variedades foram somadas para não haver desvio de informação sobre os produtos propriamente ditos.
A Tabela 3 apresenta 5 (cinco) produtos dos principais grupos de hortigranjeiros, escolhidos em função de sua significativa representatividade sobre a movimentação de recebimento anual de hortigranjeiros do Ceasa Minas.

Tabela 3

Movimentação Anual de Hortigranjeiros

\begin{tabular}{l|c|c}
\hline \multicolumn{1}{|c}{$\begin{array}{c}\text { Principais produtos } \\
\text { ofertados em 2011 }\end{array}$} & \multicolumn{2}{|c}{$\begin{array}{c}\text { Total de hortigranjeiros } \\
\text { (1.009.537 t./ano) }\end{array}$} \\
\hline Produtos amostrados & Toneladas & $\%$ \\
\hline Batata lisa & 188.922 & 18,71 \\
\hline Tomate ( LV) & 100.453 & \\
\hline Tomate (SC) & 34.282 & \\
\hline Total de tomate & 134.735 & 13,35 \\
\hline Banana (Pt) & 70.720 & \\
\hline Banana (Nn) & 52.550 & \\
\hline Total de banana & 123.270 & 12,21 \\
\hline Repolho hibrido & 50.226 & 4,98 \\
\hline Ovos de granja & 33.891 & 3,36 \\
\hline Total & 531.044 & 52,60 \\
\hline
\end{tabular}

Fonte: CEASA MINAS, 2012.

Adaptado por: Sérgio Gontijo Faria

Em função dos dados existentes, com informações disponíveis para o período de 1981 a 2012, optou-se mais uma vez por trabalhar usando-se o sistema de amostragem intencional. Sendo assim, o ano inicial escolhido foi de 1982, para atender a um intervalo de 10 anos, sendo 2012 o último ano analisado.

A apresentação dos resultados deste trabalho foi por intermédio de mapas e gráficos. Para tanto, foram utilizados os programas ArcGis, CorelDraw e Excel, que representaram a situação analisada, permitindo uma análise da hipótese de centralidade em relação aos fluxos de hortigranjeiros no atual do sistema Ceasa Minas. 


\section{ANÁLISE DE DADOS}

$\mathrm{Na}$ representação dos dados através de mapas, verificou-se a ocorrência de fatos curiosos, como os municípios produtores de repolho que também são produtores de tomate (Carandaí, Barbacena e Lagoa Dourada) sendo representados nos mapas com dois fluxos diferentes.

Inicialmente pôde-se observar, através dos mapas das figuras 1, 2, 3 e 4, a questão do grande volume de produtos em movimento, pois o fluxo de hortigranjeiros no entreposto é diário, embora os dados utilizados neste trabalho estejam apresentados na forma de registros anuais. Ressalta-se que os cinco produtos trabalhados (banana, batata, repolho, tomate e ovos) aparecem em todas as amostras de forma volumosa, pois foram considerados os municípios produtores que atingiram quantidades superiores a três mil toneladas, durante um período maior que sete meses no ano.

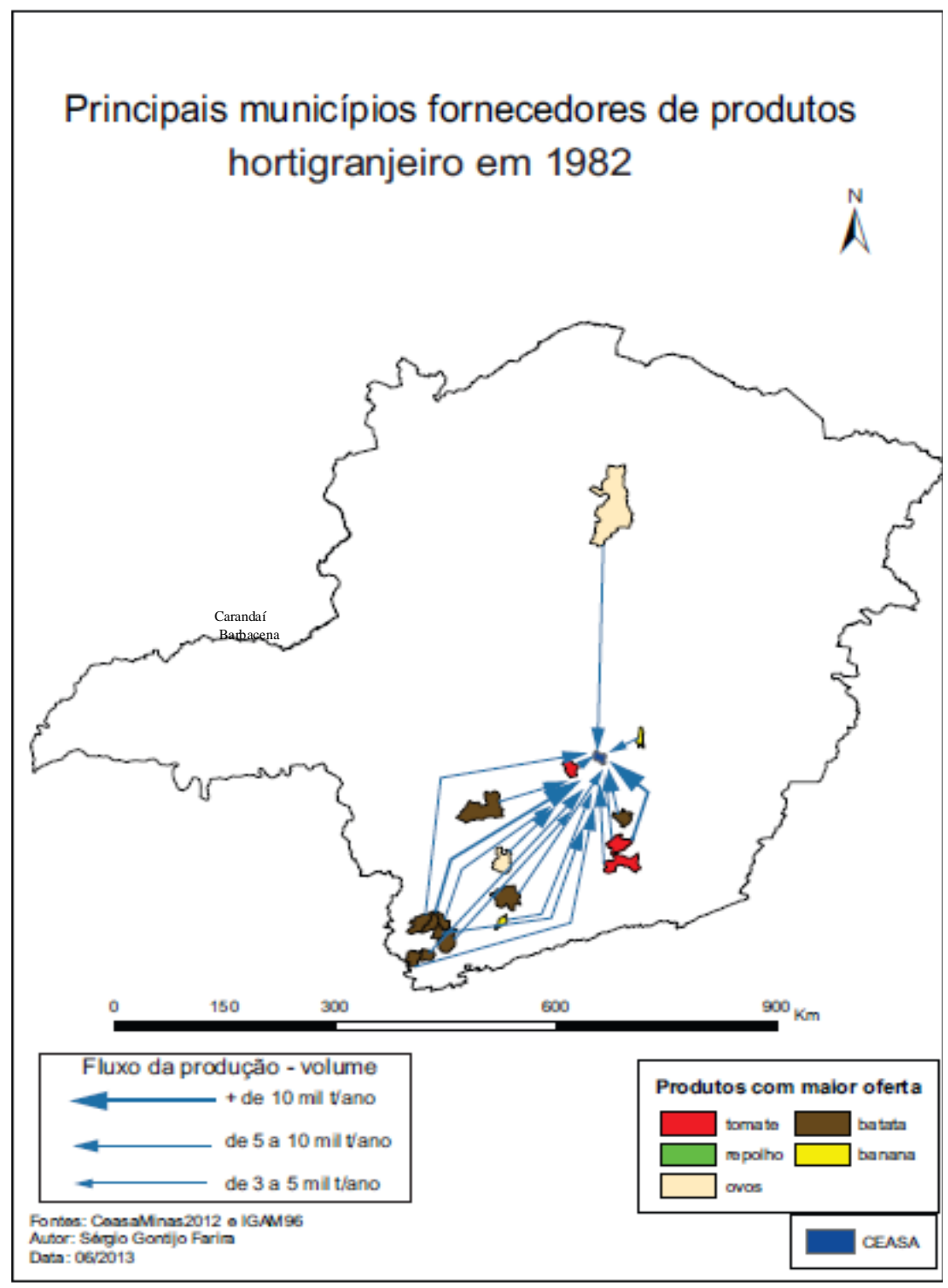

Figura 1 - Mapa de fluxos hortigranjeiros, 1982 Elaborado por Sérgio Gontijo Faria 


\section{Principais municípios fomecedores de produtos hortigranjeiros em 1992}

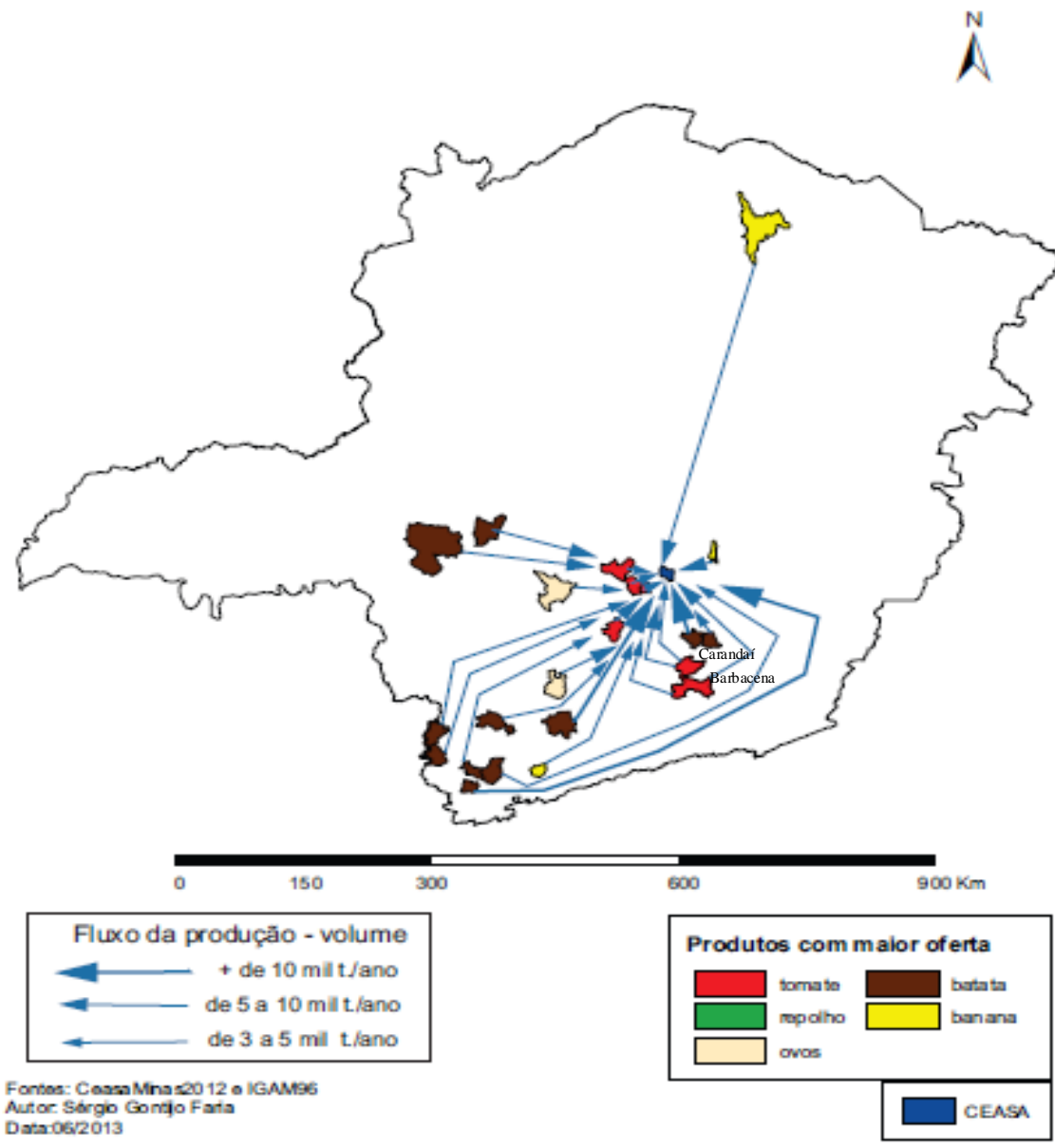

Figura 2 - Mapa de fluxos hortigranjeiros, 1992 Elaborado por Sérgio Gontijo Faria

A alteração das zonas produtoras de hortigranjeiros foi uma das características observadas nos mapas produzidos. Por exemplo, banana e batata são produtos mais volumosos e tiveram uma alteração mais nítida, com sua maior produção passando do Sul de Minas para as regiões Norte e Centro Oeste. O tomate e o repolho mantiveram-se na região Central, provavelmente por questões ligadas à própria resistência degenerativa dos produtos que necessitam de uma maior proximidade do ponto de distribuição. A produção de ovos também se deslocou do Norte de Minas para a região Centro Oeste e posteriormente do Centro Oeste para o Sul de Minas. 
Principais municípios fornecedores de produtos hortigranjeiros em 2002

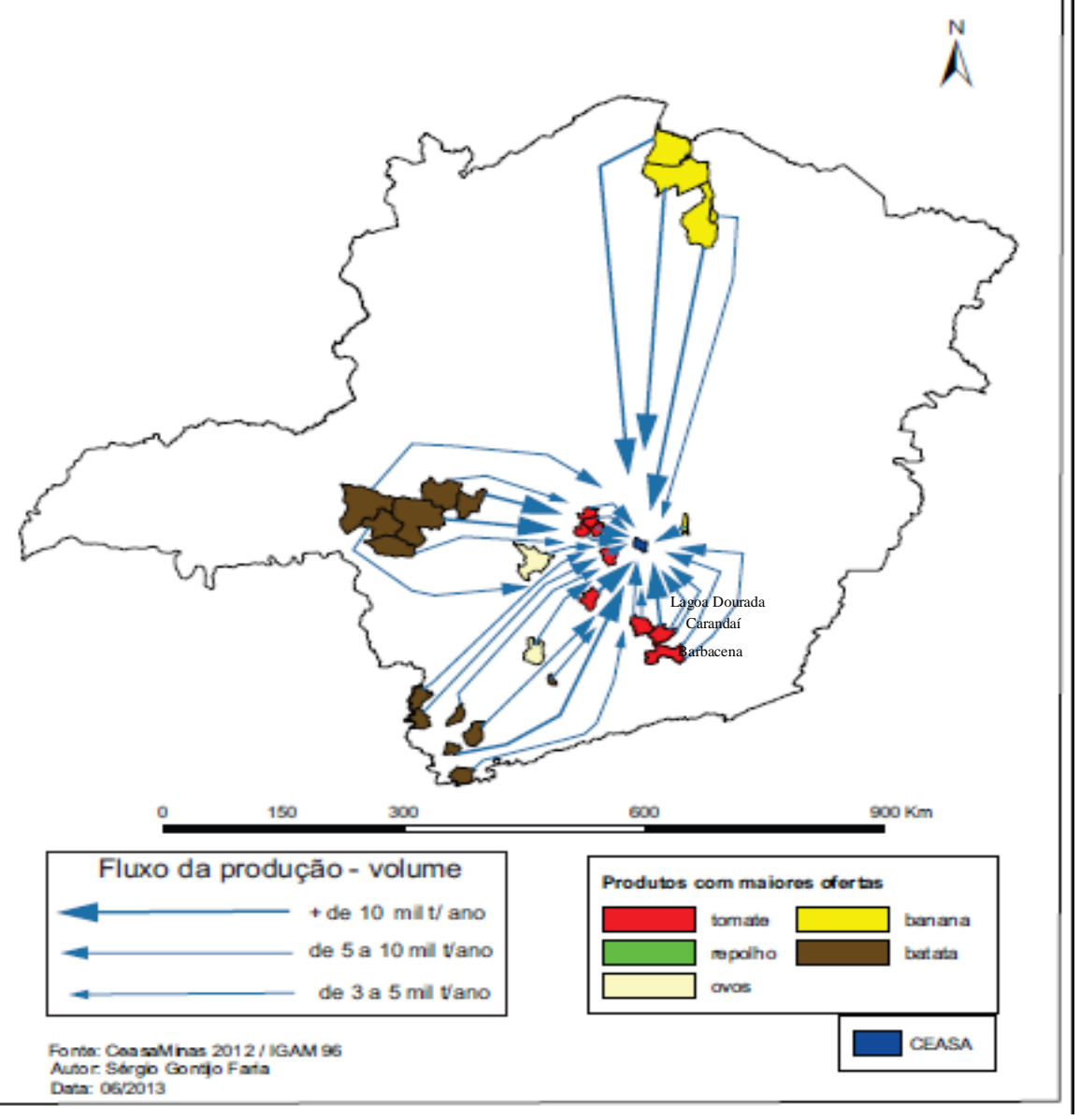

Figura 3 - Mapa de fluxos hortigranjeiros, 2002 Elaborado por Sérgio Gontijo Faria 


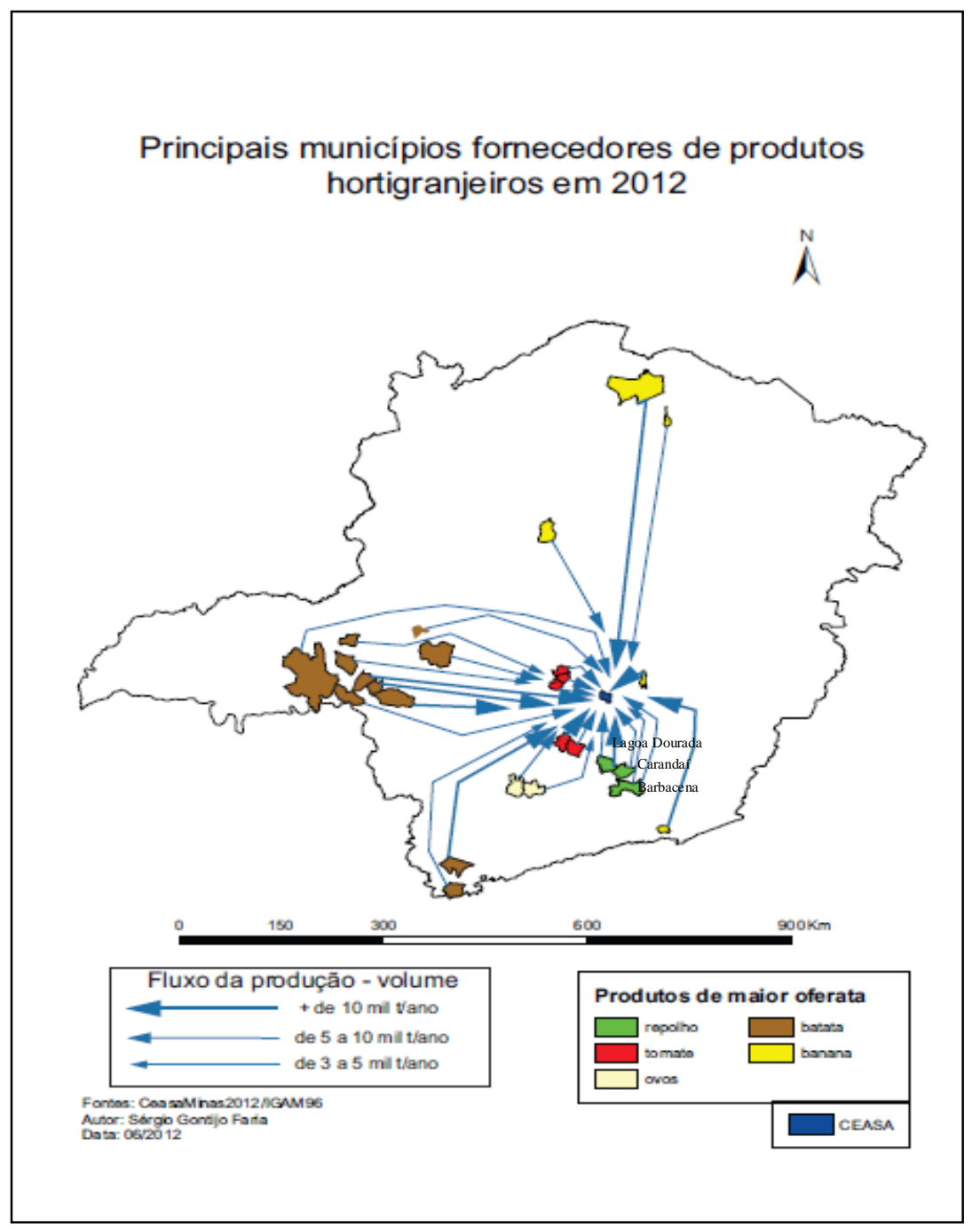

Figura 4 - Mapa de fluxos hortigranjeiros, 2012 Elaborado por Sérgio Gontijo Faria

Considerando os embasamentos teóricos deste trabalho, pode-se verificar que tanto a diversidade quanto o volume direcionado à Central de Distribuição de Minas Gerais indicam que este entreposto incorpora as características de um lugar central. $O$ direcionamento crescente da produção de hortigranjeiros para a Ceasa Minas configura a centralidade do entreposto de Contagem em relação aos Fluxos destes produtos. A evolução do fluxo de hortigranjeiros é nítida na comparação entre os mapas das figuras 1 e 4 , o que vem mais uma vez evidenciar a centralidade da captação de hortigranjeiros em Minas Gerais, no entreposto da Ceasa Minas de Contagem.

A análise das vias de acesso apenas confirma o crescimento do fluxo de hortigranjeiros para o entreposto de Contagem advindo de todas as regiões produtoras. As distâncias em questão mantêm uma média razoável, conforme observado na Figura 5, o que proporciona condições de atendimento ao mercado em tempo hábil. 


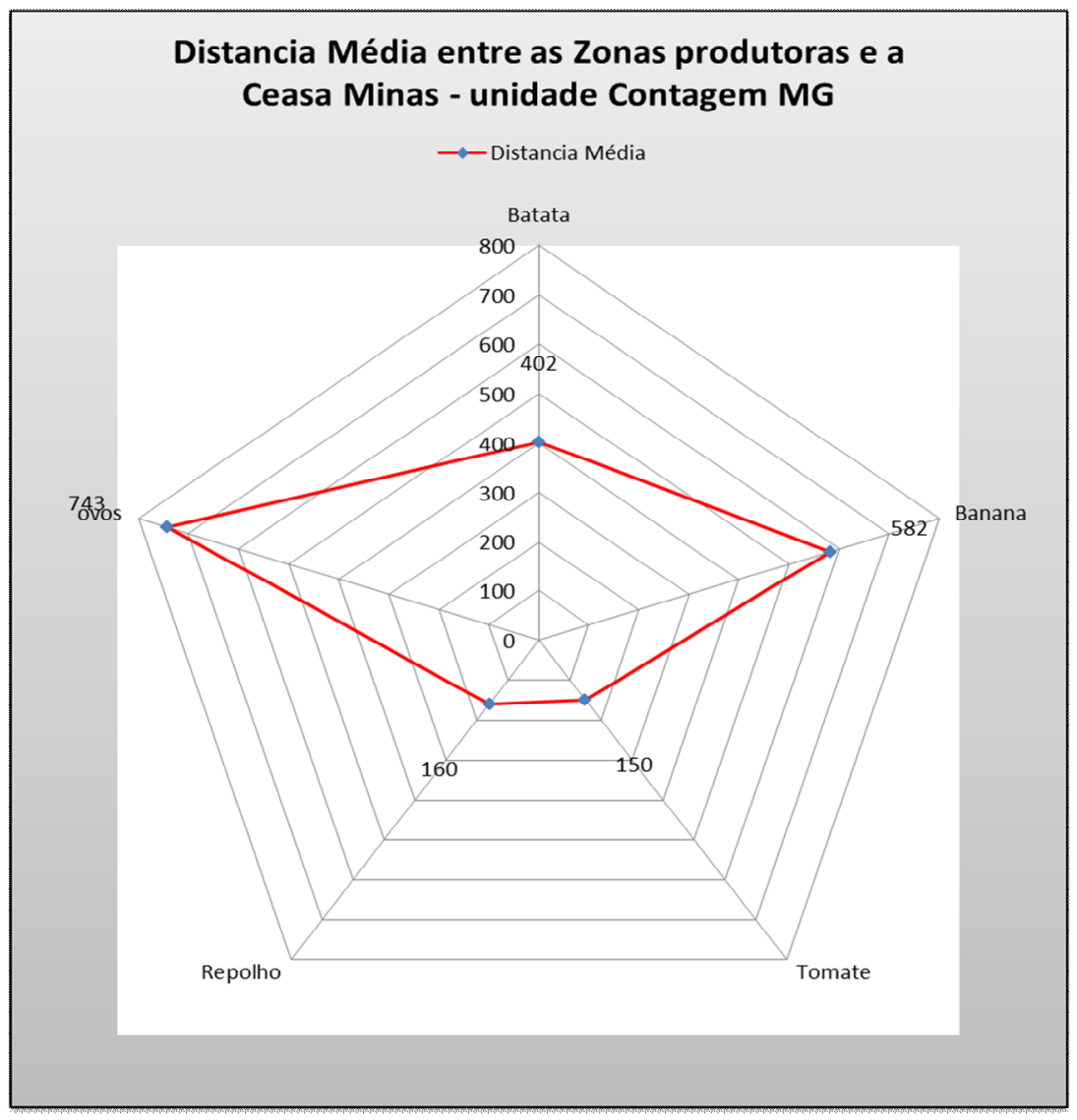

Figura 5 - Gráfico de Distâncias

Elaborado por Sérgio Gontijo Faria

No levantamento dos dados foi identificado que a participação das unidades do interior é essencialmente regional, ocorrendo frequentemente 0 recebimento de diversos produtos procedentes da Unidade da Ceasa Minas em Contagem. A contabilidade desta movimentação mostra que apenas a unidade de Uberlândia apresenta números relevantes numa escala geral no que se refere a municípios fornecedores obtendo aproximadamente $25 \%$ do total. O dado mais relevante na análise no nível do Estado é certamente a quantidade comercializada, que mostra que a unidade de Contagem detém $85 \%$ de todo 0 volume comercializado em Minas Gerais.
Desta forma fica bem claro que a participação das unidades do interior é essencialmente regional, fato que não descaracteriza sua função de Central de Distribuição, pois a abrangência regional é também importante na distribuição, pois reduz a distância de distribuição, o que pode reduzir custos e aumentar a qualidade do produto para o consumidor.

\section{CONSIDERAÇões FinaIS}

A proposta deste trabalho era confirmar ou rejeitar a hipótese de que a Ceasa Minas poderia ser considerada como um local que mantém a centralidade dos fluxos de hortigranjeiros no Estado de Minas Gerais. 
Esta pesquisa demonstrou que, em relação à diversidade ou volume dos produtos comercializados, a Central de Distribuição de Minas Gerais incorpora, efetivamente, as características de um lugar central, ficando evidente a sua centralidade em relação aos fluxos e fixos de hortigranjeiros no Estado de Minas Gerais.

\section{REFERÊNCIAS}

ABRACEN. Manual Operacional das Ceasas do Brasil: Conceitos das Ceasa. Belo Horizonte: AD2, $2011.233 \mathrm{p}$.

BEAUJEU-GARNIER, J. Geografia Urbana. Tradução de Raquel Soeiro de Brito. 2. ${ }^{a}$ ed. Lisboa: Fundação Calouste Gulbenkian 1997.525 p. Versão português. Original francês.

CEASA MINAS. Ceasa Minas. Apresentação do Ceasa Minas informes hortigranjeiros, institucional. Disponível em: $<$ http://www.ceasaminas.com.br/relatorios gestao.asp ?ds foto=\&id quem=101 >. Acesso em: 03 Mar. 2012.

COCCO, R. G. Planejamento de transporte e estruturação urbana: possíveis contribuições da geografia para o planejamento dos transportes públicos. UNESP, Presidente Prudente. EGAL. 2009.

CUNHA, A. R. A. A.; CAMPOS, J. B. O Sistema de Abastecimento Atacadista no Brasil: uma rede complexa de logística.2009. Abracen.14p

DUARTE, R. G. Centralidade, acessibilidade e o processo de reconfiguração do sistema de transporte na metrópole carioca dos anos de 1960; Revista território. Rio de Janeiro; ano VII- n. ำ 11,12 e 13 set/out, 2003.
IBGE - INSTITUTO BRASILEIRO DE GEOGRAFIA E ESTATÍSTICA - Estados@. Disponível em: http://www.ibge.gov.br/estadosat/perfil.php?sigla=mg Acesso em 22 de junho 2013.

LEFEBVRE, H. A Revolução Urbana. A Forma Urbana. UFMG Belo Horizonte. 2008. 3ª reimpressão.

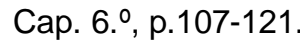

MARTINS, S. S. Itatiaia Móveis de Aço s/a: Um Fixo Transformador do Espaço. UFV, Centro de Ciências Humanas, Letras e Artes Departamento de Artes e Humanidades Curso de Geografia. Viçosa, MG, 2006.

PROHORT. Diagnóstico dos mercados atacadista de hortigranjeiros. Brasilia: Conab, 2010. 39p.

SANTOS, M. Espaço e método. $4^{a}$ ed. São Paulo: Nobel, 1997, 88p.

SÃO PAULO MINHA CIDADE. Prefeitura de São Paulo. Secretária Municipal de Turismo.

Apresentação de Pontos turísticos, história da cidade, fotos, musicas, característica regionais. Disponível em: <http://www.saopaulominhacidade.com.br/list.asp?!D= 7040>. Acesso em: 16 maio 2012. 